\title{
Antibiotic Resistance and Infection Control: Physicians Aspects and Beliefs
}

\author{
Milori Ariana* and Miliori Eleftheria \\ Department of Microbiology, General Hospital of Messolonghi, Greece
}

*Corresponding author: Milori Ariana, Department of Microbiology, General Hospital of Messolonghi, Greece, Tel: 00306983913128; E-mail: arianamilori@gmail.com

Received date: March 19, 2017; Accepted date: April 21, 2017; Published date: April 28, 2017

Copyright: (c) 2017 Ariana M, et al. This is an open-access article distributed under the terms of the Creative Commons Attribution License, which permits unrestricted use, distribution, and reproduction in any medium, provided the original author and source are credited.

\begin{abstract}
Introduction: Antibiotic resistance is a global healthcare problem, strongly connected to hospital acquired infections. The aim of the study was to imprint doctors' perceptions and beliefs regarding antibiotics use and resistance, and infection prevention and control measures as well.

Material and Methods: The current study was conducted in Messolonghi hospital and in Agioi Anargiroi hospital. A specific questionnaire was administered to 123 clinicians of varying specialties, mostly interns.

Results: Drawbacks were detected in staff training in terms of proper antibiotic prescription. Their prescribing decisions were mainly affected by their knowledge, training and their previous experience. The vast majority of the participants consider antibiotic resistance as a serious national problem, driven by antibiotic overprescribing. They also believe hospital acquired infections are a serious health problem, with major effects on healthcare quality and cost. However, few successfully responded in the relative questionnaire regarding patient colonization from nosocomial pathogens and although they were informed about Personal Protective Measures, few had knowledge of their proper use.
\end{abstract}

Discussion: This study indicates that the application of coordinated antimicrobial programs (antibiotic stewardship) as well as clinician training in infection prevention and control is imperative for Public Hospitals in Greece.

Keywords: Antibiotic use; Antimicrobial resistance; Antibiotic prescribing; Hospital acquired infections; Personal protective measures

\section{Introduction}

Antibiotic resistance is nowadays a vast problem, a hazard for healthcare systems worldwide, rising at an alarming rate [1-3]. Previous studies have proved that antibiotic overconsumption has a prominent position among its causes [4-6], followed by inappropriate antibiotic prescribing and by providing antibiotics without prescription $[1,2,4,7,8]$. Treatment of common infections will be a challenge as few new antibiotics are being developed, limiting the prescribing choices $[9,10]$. Multi-resistant microorganisms are the cause of many hospital acquired infections, a leading cause of morbidity and mortality $[11,12]$. This study emphasizes on physician aspects and beliefs regarding the previous problems at a Greek provincial hospital, aiming to provide feedback about their practices and possibly to indicate potential solutions that can improve healthcare quality.

\section{Participants and Methods}

The survey took place from March 2015 to March 2016. A total of 130 questionnaires were distributed among every physician of General Hospital of Messolonghi and of General Oncology Hospital Agioi Anargyroi, with the permission of the scientific committees of both hospitals. The response rate was $94.6 \%$ (123 were returned complete).

Information about physician perceptions of antibiotic resistance was collected using a self-administered questionnaire. The questionnaire was divided in 6 parts which include demographic questions, questions on decision making, on physician perceptions of the importance of the problem of antibiotic resistance and antibiotic prescribing, as well as questions on their attitudes regarding current and potential practices to solve the problem. Permission was asked and granted through email from the author T. Evans in order to use the first 14 questions [13]. The questions included were either closed type questions or they used a five point Likert style response. The last two scales were prepared by the authors of this report and include seven closed type questions about hospital acquired infections (HAIs) and Personal Protective Measures (PPMs).

Descriptive and inferential statistics were used to present the results of the survey, including frequencies, means and SDs, chi-square tests and cross-tab analysis. The significance level used was 0.05 .

\section{Results}

Among the 123 physicians $52 \%$ were residents (64), $12.2 \%$ were clinic directors (15) and 35.8\% were consultants A and B (44). Regarding their residency there were $33(26.8 \%)$ pathologists, 19 (15.4\%) surgeons and 17 (13.8\%) general physicians.

\section{Physician's prescribing habits}

Most of the physicians (82.9\%) had prescribed antibiotics the past six months. Over the past seven days, $39.8 \%$ (47) of the physicians had prescribed once or twice and $32.2 \%$ (38) of the physicians had written three to five prescriptions. Physicians appeared confident in making a choice between intravenous or per os administration (30.1\% claimed very confident), in choosing a combination therapy if appropriate 
Page 2 of 3

( $25.2 \%$ claimed very confident) and in planning the duration of the treatment using the correct antibiotic dose.

They felt less certain about their choice of antibiotic treatment and about not prescribing antibiotics for patients with fever but without severity criteria, or if they are not sure about the diagnosis. Their prescribing decisions were mainly affected by their knowledge, training and their previous experience $(76.4 \%, 94)$, followed by advice from microbiologists $(24.4 \%, 30)$, national protocols' use $(22.8 \%, 28)$ and advice from senior, more experienced colleagues $(22.8 \%, 24)$. Experience appeared to be more important for consultants B and senior colleague advice more important for residents.

\section{Prevalence of antibiotic resistance and its causes}

Antibiotic resistance was considered a national problem by nearly all of the participants $(92.7 \%)$, and it was considered as a problem in their hospital and in their clinical practice by $65.9 \%$ and $63.4 \%$ of them respectively. In order to evaluate the accuracy of their knowledge, the prevalence of resistant $E$. coli and $K$. pneumoniae strains was calculated in G.H. of Messolonghi. Physicians tended to underestimate the prevalence of carbapenem resistant $K$. pneumoniae strains whereas their estimates for cefuroxime and ciprofloxacin resistant $E$. coli strains were mostly correct.

As a potential cause for antibiotic resistance $99.2 \%$ of the physicians considered very important the problem of antibiotic overprescribing, followed by the excessive use of broad spectrum antibiotics (95.9\%). It is believed by $32.5 \%$ of the physicians that $10-20 \%$ of the antibiotics prescribed are unnecessary and by $28.5 \%$ of the physicians that this percentage lies between 20\%-50\%.

Younger physicians tend to believe that the rate of unnecessary prescriptions is between $10 \%-50 \%$, while half of the clinic directors estimate this rate to be below $10 \%$.

\section{Interventions}

To improve the efficiency of the prescription process, the overwhelming majority of the physicians consider educational sessions (93\%), availability of national protocols (93.5\%), availability of national resistance data (95\%) and readily accessible advice from ID specialists (91\%) to be important interventions. Although $93 \%$ of the physicians consider educational sessions very important interventions, only $34 \%$ of them have received training over the past year. Effective are also considered readily accessible advice from infection prevention and control team (84\%), readily accessible advice from clinical microbiologists (83\%) and advice from senior colleagues (67\%).

Advice from a pharmaceutical representative was not considered important by $83 \%$ of the physicians. Table 1 contains the results of the statistical analysis performed. Statistically significant results for gender differences occurred regarding only readily accessible advice from ID specialist $(\mathrm{p}=0.013)$ and readily accessible advice from clinical microbiologist $(\mathrm{p}=0.000)$.

Both interventions were considered more important from women than from men physicians. Consultant physicians consider more important the restriction of prescription of certain antibiotics $(\mathrm{p}=0.001)$ and the restriction of prescription of all antibiotics $(\mathrm{p}=0.005)$, compared to the perceptions of residents, less experienced consultants and clinic directors.

\begin{tabular}{|c|c|c|c|c|}
\hline \multirow{2}{*}{ Perceptions } & \multicolumn{2}{|c|}{$\begin{array}{l}\text { Physician's title } \\
\text { differences }\end{array}$} & \multicolumn{2}{|c|}{ Gender differences } \\
\hline & $\mathbf{F}$ & Sig & $\mathbf{T}$ & Sig \\
\hline $\begin{array}{l}\text { Educational sessions on } \\
\text { prescribing }\end{array}$ & 1.591 & 0.195 & 1.788 & 0.184 \\
\hline $\begin{array}{l}\text { Availability of local/national } \\
\text { protocols/guidelines }\end{array}$ & 0.089 & 0.966 & 0.39 & 0.533 \\
\hline $\begin{array}{l}\text { Availability of local/national } \\
\text { resistance data }\end{array}$ & 1.726 & 0.165 & 0.038 & 0.845 \\
\hline Computer aided prescribing & 2.101 & 0.104 & 0.527 & 0.469 \\
\hline $\begin{array}{l}\text { Presence of an antimicrobial } \\
\text { management team }\end{array}$ & 0.941 & 0.423 & 0.786 & 0.377 \\
\hline $\begin{array}{l}\text { Readily accessible advice } \\
\text { from ID specialist }\end{array}$ & 0.643 & 0.589 & 6.332 & 0.013 \\
\hline $\begin{array}{l}\text { Readily accessible advice } \\
\text { from clinical microbiologist }\end{array}$ & 1.678 & 0.176 & 13.513 & 0 \\
\hline $\begin{array}{l}\text { Readily accessible advice } \\
\text { from pharmacist }\end{array}$ & 0.835 & 0.477 & 0.049 & 0.825 \\
\hline $\begin{array}{l}\text { Readily accessible advice } \\
\text { from infection prevention and } \\
\text { control team }\end{array}$ & 1.168 & 0.325 & 0.308 & 0.58 \\
\hline Advice from senior colleagues & 2.522 & 0.061 & 0.657 & 0.419 \\
\hline $\begin{array}{l}\text { Speaking to a pharmaceutical } \\
\text { representative }\end{array}$ & 1.776 & 0.156 & 0.359 & 0.55 \\
\hline $\begin{array}{l}\text { Restriction of prescription of } \\
\text { certain antibiotics }\end{array}$ & 5.72 & 0.001 & 1.532 & 0.218 \\
\hline $\begin{array}{l}\text { Restriction of prescription of } \\
\text { all antibiotics }\end{array}$ & 4.466 & 0.005 & 2.255 & 0.136 \\
\hline $\begin{array}{l}\text { Regular audit and feedback } \\
\text { on antibiotic prescribing on } \\
\text { your ward }\end{array}$ & 1.959 & 0.124 & 0.02 & 0.888 \\
\hline
\end{tabular}

Table 1: Differences in physician's perceptions on possible interventions based on title and gender differences.

\section{Personal protective measures and colonization surveillance}

Moving to the last topic of the questionnaire, almost all of the physicians $(95.9 \%, 118)$ believe that infections in Greece are a serious national problem with major effects on healthcare quality and cost. Even though $56.10 \%$ of them consider their knowledge on prevention of hospital acquired infections satisfactory, $60.98 \%$ of them have not attended any training course on that topic (Figure 1). Only 15\% chose the correct answer combination when asked in which cases colonization surveillance should be done for hospitalized patients. Clinic directors gave a higher percentage of correct answers followed by consultants A. Significantly more men than women answered incorrectly that colonization surveillance should be done for every patient at the time of hospital admission ( $\mathrm{p}=0.013)$. Moreover, although $80 \%$ of the participants were aware of the PPMs against multidrug resistant strains, only $12 \%$ knew the application process of the equipment and only $24 \%$ knew how to safely remove it. Clinic directors were more informed about colonization surveillance and younger physicians were more informed about PPMs. No participant answered correctly all of the questions on this topic. 


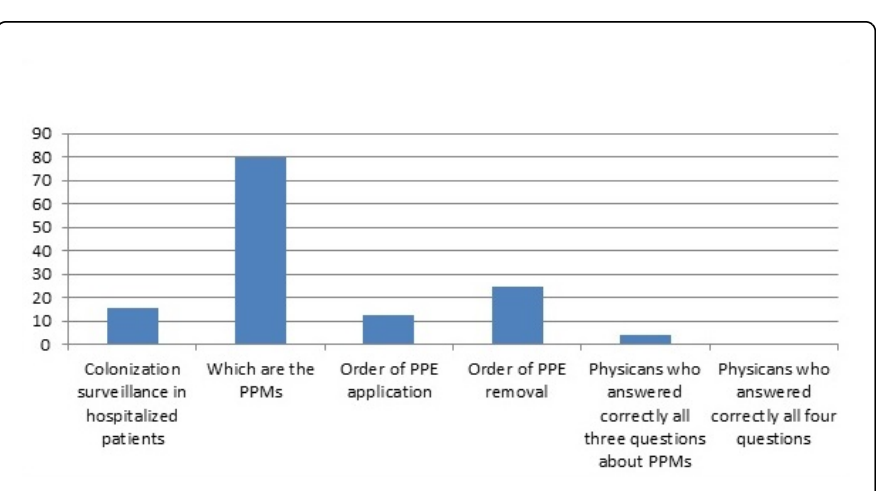

Figure 1: Physicians knowledge about prevention and control measures to limit the spread of antibiotic resistant infections.

\section{Discussion}

Our survey focused on physicians' attitudes on the problem of antibiotic resistance and on their knowledge on HAIs at two hospitals. The results were indicative of the problem of over prescription in Greece over the past years which is perceived by the majority of the physicians as a contributing factor to antibiotic resistance. Regarding HAIs, physicians were aware of the importance of the problem in this country and were familiar with the PPMs. However, few had received training on HAIs and fewer knew how to use PPMs.

The prescription rate in Greece exceeds $55 \%$ compared to an average of $35 \%$ in other European countries [14]. According to ECDC records for the year 2011-2012, 82\% of the prescribed quinolones were of second-generation and the remaining $18 \%$ were of third generation [14]. This is reflected in physician's answers at the questionnaire and almost $70 \%$ of them believe that reducing antibiotic prescription would prove effective in regulating antibiotic resistance. The majority of the physicians had prescribed antibiotics the past six months, a practice that is considered to be a safer and more secure choice for treatment outcome [15]. Their prescribing choices were mostly affected by their clinical experience, their personal knowledge and training, necessary factors to prevent the spread of multidrug-resistant pathogens [16]. Studies from international bibliography revealed that residents are more easily affected by senior colleagues advice [17], a finding that matches our study results.

An alarmingly high percentage of the participants had not received the necessary education on the process of prescribing and on HAI control measures. Successful prevention of HAIs requires a coordinated system of parallel actions, including training of healthcare officials on antibiotic prescribing [16]. This study indicates the urgency to conduct often training sessions on this topic, a neglected act in our hospitals.

In an effort for improvement, the greek ministry of health's action plan named "prokroystis" aims to prevent HAIs from multi-resistant gram negative pathogens by emphasizing on the importance and the implementation of hand hygiene and PPMs, as well as the surveillance of multi-resistant gram negative bacteria, among others [16]. This will lead to the creation of a national database with feedback from clinical surveys and also to the compliance of hospital personnel to gradually reduce HAIs and the growth of multi-resistant pathogens [16].

\section{References}

1. http://www.who.int/mediacentre/factsheets/antibiotic-resistance/en/

2. http://www.who.int/mediacentre/factsheets/fs194/en/

3. http://apps.who.int/iris/bitstream/ 10665/112642/1/9789241564748_eng.pdf

4. http://www.cdc.gov/drugresistance/threat-report-2013.

5. Read AF, Woods RJ (2014) Antibiotic resistance management. Evol Med Public Health. 2014: 147.

6. Murray BE (1994) Can antibiotic resistance be controlled? N Engl J Med 330: 1229-1230.

7. Michael CA, Dominey-Howes D, Labbate M (2014) The antibiotic resistance crisis: Causes, consequences, and management. Front Public Health 2: 145.

8. Luyt CE, Brechot N, Trouillet JL, Chastre J (2014) Antibiotic stewardship in the intensive care unit. Crit Care 18: 480.

9. Gould IM, Bal AM (2013) New antibiotic agents in the pipeline and how they can overcome microbial resistance. Virulence 4: 185-191.

10. Williams KJ, Bax KP (2009) Challenges in developing new antibacterial drugs. Curr Opin Investig Drugs 10: 157-163.

11. Kowalski WJ (2007) Air-treatment systems for controlling hospitalacquired infections. HPAC Engineering.

12. Kevin L, Sotiris S, Juan S (2012) Hospital-Acquired infections. Surgical Clinics of North America.

13. Wester CW, Durairaj L, Evans TA, Schwartz DN, Husain S, et al. (2002) Antibiotic resistance: A survey of physician perceptions. Arch Intern Med 162: 2210-2216.

14. ECDC Surveillance Report (2013) Point prevalence survey of healthcare associated infections and antimicrobial use in European acute care hospitals 2011-2012. Stockholm, Sweden.

15. Simpson SA, Wood F, Butler CC (2007) General practitioner's perceptions of antimicrobial resistance: A qualitative study. J Antimicrob Chemother 59: 292-296.

16. Keelpno (2015) Guidelines for controlling the dispersion of multi-drug resistant pathogens in healthcare facilities.

17. Mattik K, Kelly N, Rees C (2014) A window into the lives of junior doctors: Narrative interviews exploring antimicrobial prescribing experiences. J Antimicrob Chemother 69: 2274-2283. 